\title{
Cultivo comercial de camarones Litopenaeus vannamei en Costa Rica durante El Niño 2015: incidencia de enfermedades
}

\author{
COMMERCIAL CULTURE OF SHRIMP Litopenaeus vannamei IN COSTA RICA DURING EL \\ Niño 2015: incidence of diseases
}

\author{
José A. Valverde-Moya ${ }^{1,3}$, Alexander Varela-Mejías ${ }^{2,4}$
}

\section{Resumen}

\begin{abstract}
Se estudiaron los rendimientos de producción del camarón Litopenaeus vannamei en estanques del Golfo de Nicoya, Costa Rica, para evaluar el efecto de las enfermedades diagnosticadas durante el fenómeno de El Niño 2015. Se utilizaron dos sistemas de cultivo: tres ciclos cortos (CC) al año en fincas con baja incidencia de enfermedades y dos ciclos largos (CL) al año en las fincas más afectadas con episodios de altas mortalidades. La sobrevivencia fue menor en aquellas con $2 \mathrm{CL}(35.3 \pm 3.2 \%)$ con respecto a las de $3 \mathrm{CC}$ $(63.1 \pm 3.2 \%)$. Se registró una relación inversa entre el peso promedio alcanzado a la cosecha y la densidad final de cultivo $(20.3 \pm 0.8 \mathrm{~g}$ en $2 \mathrm{CL}$ y $15.2 \pm 1.6 \mathrm{~g}$ en $3 \mathrm{CC})$ y una compensación en el crecimiento $(1.29 \pm 0.12$ y $1.08 \pm 0.10 \mathrm{~g} / \mathrm{semana}$ en $2 \mathrm{CL}$ y $3 \mathrm{CC}$, respectivamente). La producción final fue directamente proporcional a la sobrevivencia con un promedio de $717 \pm 8 \mathrm{~kg} /$ ha en 2 CL y de $941 \pm 53 \mathrm{~kg} /$ ha en $3 \mathrm{CC}$. La productividad se redujo prácticamente a la mitad en 2 CL (1434 kg/ha*año) con respecto a 3 CC (2823 kg/ ha*año). No se encontró un beneficio en la productividad al mantener los cultivos para lograr tallas más grandes con los sobrevivientes luego de eventos de mortalidad severas.
\end{abstract}

Palabras clave: camarón; Golfo de Nicoya; El Niño; rentabilidad; mortalidad

\section{Abstract}

Production yields of the marine shrimp, Litopenaeus vannamei, cultured in earthen ponds in the Gulf of Nicoya, Costa Rica were studied to evaluate the effect of diseases diagnosed during El Niño 2015 event. Two culture systems on earthen ponds were used: three short cycles (SC) per year in farms with low disease incidence and two long cycles

${ }^{1}$ Núcleo Náutico Pesquero, Instituto Nacional de Aprendizaje, Puntarenas, Costa Rica

${ }^{2}$ Laboratorio de Patologías y Parasitología de Crustáceos, Nicoya, Guanacaste, Costa Rica

${ }^{3}$ E-mail: jvalverdemoya@ina.ac.cr

${ }^{4}$ E-mail: alexander.varela@gmail.com

Recibido: 18 de mayo de 2017

Aceptado para publicación: 18 se septiembre de 2017 
(LC) per year in highly affected farms with high mortality. Survival was low in the 2 CL (35.3 $\pm 3.2 \%)$ as compared to the $3 \mathrm{CC}(63.1 \pm 3.2 \%)$. An inverse relationship between average weight at harvesting and the final culture density was obtained $(20.3 \pm 0.8 \mathrm{~g}$ in $2 \mathrm{CL}$ and $15.2 \pm 1.6 \mathrm{~g}$ in $3 \mathrm{CC})$ as well as a growth compensation $(1.29 \pm 0.12$ and $1.08 \pm 0.10 \mathrm{~g} /$ week in $2 \mathrm{CL}$ and $3 \mathrm{CC}$, respectively). The final production was directly proportional to the survival, with an average of $717 \pm 8 \mathrm{~kg} / \mathrm{ha}$ in $2 \mathrm{CL}$ and $941 \pm 53 \mathrm{~kg} / \mathrm{ha}$ in $3 \mathrm{CC}$. The production was reduced to half in the $2 \mathrm{CL}$ ( $1434 \mathrm{~kg} / \mathrm{ha} *$ year) with respect to $3 \mathrm{CC}(2823 \mathrm{~kg} /$ ha*year). No production benefit was detected by maintaining the culture to achieve larger sizes with survivors following events of severe mortalities.

Key words: shrimp; Gulf of Nicoya; El Niño; profitability; mortality

\section{INTRODUCCIÓN}

El fenómeno de El Niño afectó severamente los países centroamericanos en 2015, y Costa Rica fue uno de los más afectados. En algunas zonas del país, las condiciones fueron las más extremas registradas en décadas o siglos. Por ejemplo, el déficit de lluvias en 2015 en Liberia de Guanacaste fue el más alto del registro histórico, que data desde 1937 (Alvarado, 2015). Según el mismo autor, las condiciones anómalas empezaron en julio, mes donde se registraron menos de $2 \mathrm{~mm}$ de lluvias con respeto al promedio y fue considerado como uno de los más secos de los últimos 75 años. Este cambio climático, a su vez, generó cambios fisiológicos (crecimiento, reproducción), ecológicos (ciclos orgánicos e inorgánicos), operacionales y ocurrencia de enfermedades en especies dedicadas a cultivos acuícolas, en concordancia con lo reportado por García y Perlado (2014).

Los cambios ambientales más significativos registrados en los estanques de cultivo son la elevación de la temperatura y la salinidad del agua. Variaciones bruscas o valores extremos durante periodos prolongados causan estrés en los camarones afectando su supervivencia. El estrés altera la respuesta inmunológica, hormonal y los aspectos osmorregulatorios debilitando los individuos (Alpuche et al., 2005), haciéndolos más susceptibles al ataque de agentes patógenos
(Vincent y Lotz, 2007; Morales-Covarrubias, 2008; Varela y Peña, 2010, 2015a; Morales y Cuellar-Anjel, 2014). Asimismo, los cambios ambientales pueden desequilibrar la microbiota y alterar la proporción de las bacterias intestinales consideradas oportunistas sobre aquellas comensales o benéficas (Ye et al., 2009).

Incrementos en las salinidades y temperaturas en 2015, provocadas por el fenómeno de El Niño, intensificaron la incidencia de enfermedades bacterianas propias de la época seca como la vibriosis, causada por Vibrio spp y la hepatopancreatitis necrotizante (NHP, por sus siglas en inglés), causada por la bacteria Hepatobacter penaei, ambas endémicas en la zona (Varela y Peña, 2015a; Peña y Varela, 2016). Muchas enfermedades bacterianas tienen la capacidad de provocar altas mortalidades en camarones en estadios de poslarva y juvenil (MoralesCovarrubias, 2008). Se considera que la combinación de cambios de temperatura y salinidad pudo haber provocado el desarrollo de grandes mortandades en 2015 (Mugnier et al., 2013; Varela y Peña, 2015a).

Cuando el incremento de la mortalidad es temprano, el productor suele recurrir a alguna de las siguientes estrategias: a) cosechar de emergencia el camarón pequeño, o b) continuar el cultivo con los animales sobrevivientes. La mayoría de los productores nacionales optan por la segunda opción esperando un crecimiento compensatorio en los 
sobrevivientes y mayores ingresos por talla de cosecha. El objetivo de este estudio fue evaluar el efecto de las principales enfermedades asociadas a periodos prolongados de altas temperaturas y salinidades, por efecto del fenómeno del Niño 2015, sobre los rendimientos de producción del camarón marino Litopenaeus vannamei cultivado en estanques en el Golfo de Nicoya, Costa Rica.

\section{Materiales y Métodos}

El estudio se realizó entre febrero y diciembre de 2015 en fincas camaroneras ubicadas en el sector de Colorado de Abangares, en el Pacífico Norte de Costa Rica, sobre la margen este de la parte interna del Golfo de Nicoya $\left(85^{\circ} 4^{\prime} 40^{\prime \prime} \mathrm{W}, 10^{\circ} 8^{\prime} 40^{\prime \prime} \mathrm{Ny} 85^{\circ} 7^{\prime}\right.$ $\left.5^{\prime \prime} \mathrm{W}, 9^{\circ} 58^{\prime} 58^{\prime \prime} \mathrm{N}\right)$. Nueve fincas no fueron severamente afectadas $(<40 \%$ mortalidad) por enfermedades y utilizaron la modalidad de tres ciclos cortos (CC) al año con un volumen de producción estimado en $950 \mathrm{~kg} /$ ha. Mientras tanto, otras nueve fueron seriamente afectadas ( $>60 \%$ mortalidad) y extendieron el periodo de cultivo, realizando solo dos ciclos largos (CL) en ese año con un nivel de producción de $717 \mathrm{~kg} / \mathrm{ha}$. Los ciclos cortos de cultivo se iniciaron en febrero y los ciclos largos en marzo, concluyendo ambos a mediados de diciembre.

Las labores de cultivo en 2015 se hicieron siguiendo los métodos tradicionales bajo condiciones estandarizadas del Plan de Manejo establecido desde 2012 en esta zona del país (Valverde-Moya y Alfaro-Montoya, 2013, 2014, 2015). Las fincas camaroneras utilizaron poslarvas provenientes de la empresa Farallón (Nicaragua), y poslarvas con nauplios de origen ecuatoriano, importadas por la empresa Activos de Crustáceos del Pacífico SA, ubicada en Punta Morales de Chomes, Puntarenas.

Se utilizaron los registros diarios de temperatura y oxígeno disuelto existentes desde hace tres años y medidos mañana y tarde con equipos portátiles YSI55. La turbidez y la salinidad del agua se determinaron semanalmente con el disco de Sechii y un refractómetro, respectivamente, durante las visitas del biólogo a las fincas.

Se utilizó una tasa diaria de alimentación (TA) predeterminada, basada en un crecimiento esperado de $1.0 \mathrm{~g} / \mathrm{semana}$, una conversión alimenticia (CA) (kg de alimento consumido / kg de camarón producido) proyectada de $1.0 \mathrm{y}$ una sobrevivencia final estima$\mathrm{da}$ en $65 \%$. Las estimaciones de las sobrevivencias se hicieron mediante los muestreos poblacionales, la vigilancia de la tasa de consumo alimenticio y los reportes de mortalidades de las fincas.

La estimación del reemplazo, para la biomasa perdida durante un episodio de mortalidad temprana, se realizó comparando los promedios \pm desviación estándar de sobrevivencia (número final/número inicial *100), crecimiento semanal (peso ganado/ días*7) y conversión alimenticia ( $\mathrm{CA}=\mathrm{kg}$ alimento/kg ganados de biomasa).

El rendimiento se calculó con los kilogramos producidos por cada 1000 juveniles sembrados y con la tasa óptima de cultivo (TOC) en cada ciclo de cultivo. La TOC se calculó como el resultado de multiplicar la sobrevivencia por la tasa de crecimiento y el resultado dividido por la conversión alimenticia.

El peso promedio se midió semanalmente a partir de la tercera semana de cultivo, momento en el cual los camarones tenían tamaño suficiente para capturarlos con atarraya. La tasa específica de crecimiento (TEC) se obtuvo mediante la fórmula: TEC $(\%$ aumento en peso $(\% \mathrm{~g} /$ día $))=[(\ln \mathrm{Pf}-\ln$ Pi) / t ] x 100, donde: $\ln$ Pf y $\ln \mathrm{Pi}=$ logaritmo natural del peso húmedo final e inicial de cada semana, $\mathrm{y} \mathrm{t}=$ tiempo en días.

Ante la sospecha de enfermedades, se tomaron muestras dirigidas de 10 camarones con algún tipo de signología clínica o mori- 
bundos. El análisis en fresco se realizó en el Laboratorio de Patologías y Parasitología de Crustáceos, Nicoya, Costa Rica. Este análisis consistió en la observación en húmedo de muestras de branquias, hepatopáncreas, intestino y apéndices, bajo el microscopio de luz, para la búsqueda de parásitos, epibiontes y alteraciones anatomopatológicas asociadas a la presencia de agentes infecciosos, siguiendo las metodologías descritas por Lightner (1996) y Morales-Covarrubias (2013). Los resultados se integraron y ubicaron en una escala para lesiones en general y en el hepatopáncreas en particular, según Varela (2007) y Cuéllar-Anjel (2008):

- Grado 0 (G0): No presentan signos de infección por el agente patógeno, parásito o epicomensal. No presentan lesiones características de la enfermedad.

- G1: Presencia muy baja del patógeno, parásito o epicomensal. Se observan muy pocas lesiones características de la enfermedad.

- G2: Se observa la presencia baja y moderada del patógeno, parásito o epicomensal. Se observan lesiones ligeras o moderadas, características de la enfermedad.

- G3: Se observa la presencia moderada del patógeno, parásito o epicomensal. Se observan lesiones de moderadas a severas, características de la enfermedad.

- G4: Se observa gran cantidad del patógeno, parásito o epicomensal. Se observan severas lesiones características de la enfermedad.

Los exámenes bacteriológicos se realizaron mediante cultivos en agar TCBS (medio selectivo diferencial para especies del género Vibrio) en muestras de hepatopáncreas. Se cuantificaron las unidades formadoras de colonias (UFC) expresadas como UFC/g de tejido. Los resultados se ubicaron en una escala de grado de severidad (Varela, 2007) siguiendo la metodología descrita por Prieto y Rodríguez (1993) y Lightner (1996).

Los análisis por histología rápida se realizaron en muestras sospechosas a infecciones por el virus de la mancha blanca, según la metodología descrita por Lightner (1996). Los resultados se presentan en una escala como positivos, sospechosos o de infección no detectada (Varela, 2007).

\section{Resultados}

Las lecturas mensuales matutinas de la temperatura y salinidad durante los últimos tres años se presentan en las figuras 1 y 2 , respectivamente. Según las mediciones de temperatura y salinidad reportadas en este estudio, 2015 puede ser catalogado como un año de sequía en la provincia de Guanacaste, Costa Rica. El fenómeno de El Niño no afectó mayormente a la región en los primeros meses del año, pero en los meses siguientes (agosto-octubre) las temperaturas fueron considerablemente más elevadas que en 2014. La temperatura del agua se incrementó cerca de $1{ }^{\circ} \mathrm{C}$ de abril a junio en 2014 y 2015 con respecto a esos meses en 2013; el incremento fue cerca de $2{ }^{\circ} \mathrm{C}$ de julio a octubre en 2014 y $2.5^{\circ} \mathrm{C}$ en 2015 con relación a esos mismos meses en 2013. En noviembre las diferencias se redujeron a $1.5{ }^{\circ} \mathrm{C}$ y en diciembre solo fue superior en 2014. Por otro lado, 2015 presentó una temperatura anormalmente cálida (superior a $1^{\circ} \mathrm{C}$ ) durante agosto a octubre en relación con 2014 , pero fue similar en noviembre e inferior en diciembre.

La salinidad en 2015 fue mayor con respecto a 2013 y 2014 desde el inicio del cultivo (entre marzo y noviembre). Se registró un aumento en la salinidad de 5 a $9 \mathrm{~g} / 1$ entre marzo y abril de 2015 con respecto a esos meses en los dos años previos. Posteriormente, la salinidad se incrementó a $12 \mathrm{~g} / 1$ entre mayo y junio, llegando a la máxima diferencia (16-18 g/l) en julio. Entre agosto y setiembre la superioridad fue cercana a $12 \mathrm{~g} / \mathrm{l}$, llegando a $5 \mathrm{~g} / 1$ en noviembre.

Los valores de los parámetros fisicoquímicos se presentan en el Cuadro 1 . Las temperaturas más bajas $\left(<30{ }^{\circ} \mathrm{C}\right)$ se pre- 


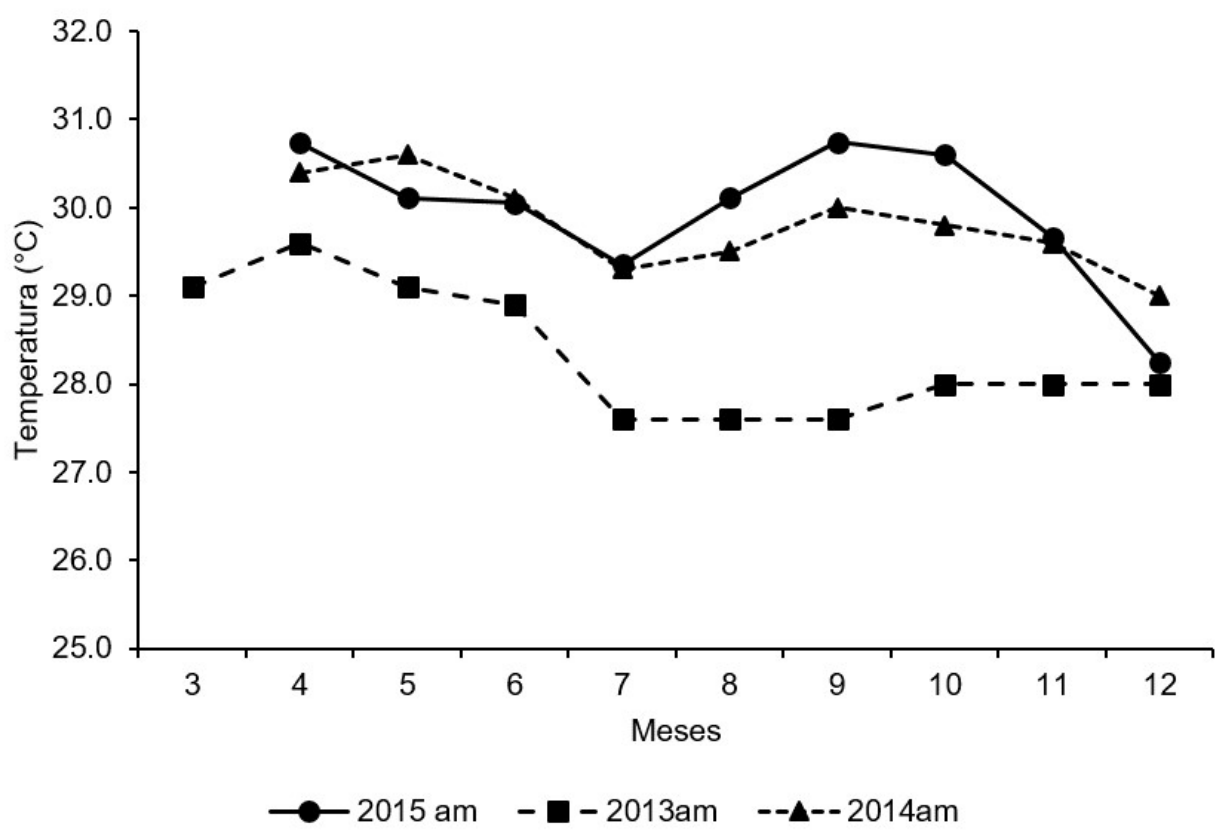

Figura 1.Fluctuación mensual de la temperatura $\left({ }^{\circ} \mathrm{C}\right)$ medida en las mañanas durante los años 2013, 2014 y 2015 en fincas camaroneras en el Golfo de Nicoya, Costa Rica

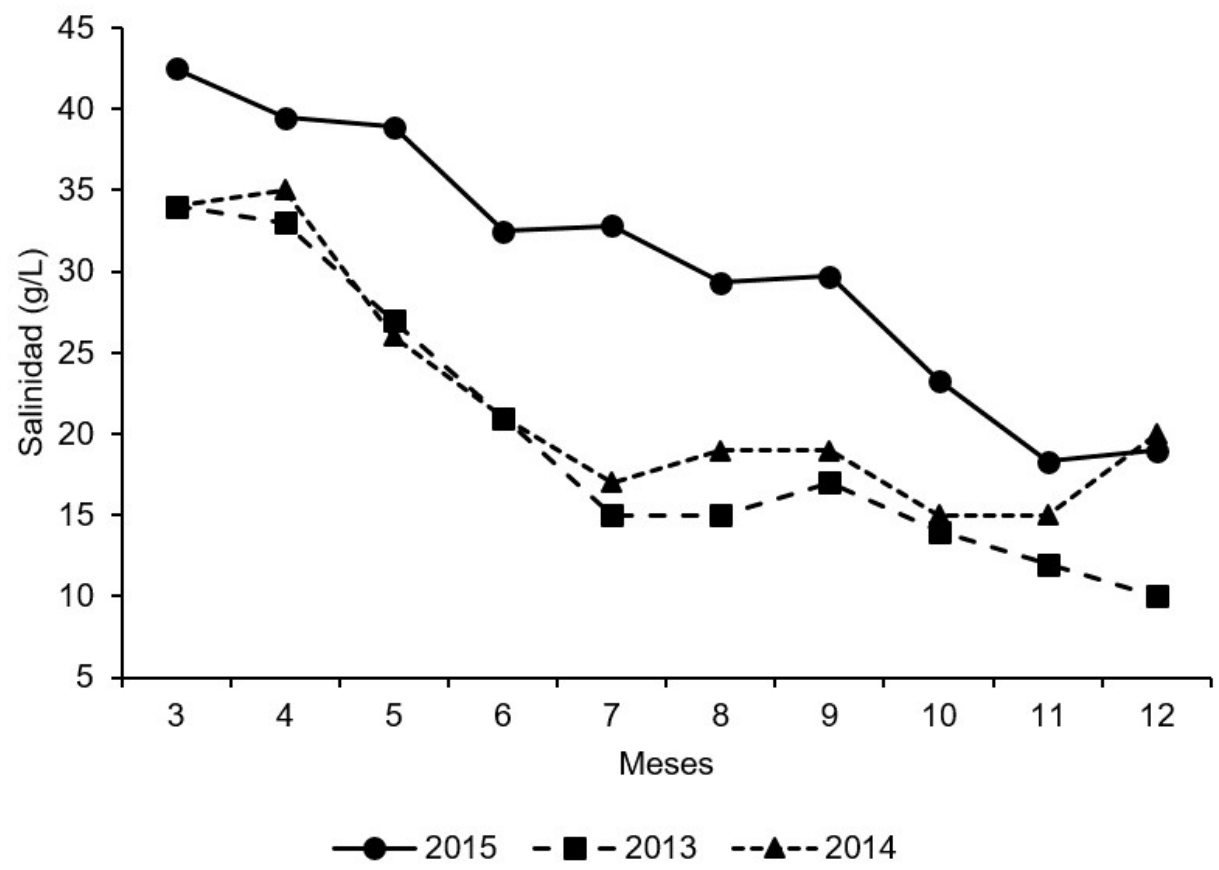

Figura 2. Fluctuación mensual de la salinidad (g/l) durante los años 2013, 2014 y 2015 en fincas camaroneras en el Golfo de Nicoya, Costa Rica 
Cuadro 1. Valores promedio de parámetros físicoquímicos del agua (media y desviación estándar) durante los meses de estudio en 2015 (mañana [am] y tarde [pm])

\begin{tabular}{cccccccccccc}
\hline & \multirow{2}{*}{$\begin{array}{c}\text { Turbidez } \\
\text { Meses }\end{array}$} & \multicolumn{3}{c}{$\begin{array}{c}\text { Temperatura } \\
\left({ }^{\circ} \mathrm{C}\right)\end{array}$} & \multicolumn{4}{c}{$\begin{array}{c}\text { Oxígeno disuelto } \\
(\mathrm{mg} / \mathrm{l})\end{array}$} \\
\cline { 2 - 12 } & \multicolumn{3}{c}{ disco de Sechii) } & \multicolumn{2}{c}{ am } & \multicolumn{2}{c}{ pm } & am & pm \\
\cline { 2 - 12 } & Media & D.E. & Media & D.E. & Media & D.E. & Media & D.E. & Media & D.E. \\
\hline 4 & 47.0 & 2.7 & 29.6 & 0.7 & 32.3 & 0.8 & 3.64 & 0.21 & 6.71 & 0.38 \\
5 & 45.7 & 3.3 & 30.2 & 0.2 & 33.2 & 0.3 & 2.69 & 0.46 & 7.33 & 0.93 \\
6 & 44.9 & 13.1 & 30.0 & 0.9 & 32.3 & 0.9 & 4.24 & 0.23 & 6.35 & 0.27 \\
7 & 39.2 & 6.4 & 29.5 & 0.4 & 31.9 & 0.4 & 4.05 & 0.18 & 6.28 & 0.51 \\
8 & 47.1 & 1.7 & 30.3 & 0.6 & 34.2 & 1.7 & 4.97 & 2.70 & 6.65 & 0.90 \\
9 & 44.6 & 1.0 & 30.4 & 0.7 & 33.4 & 0.9 & 3.03 & 0.12 & 7.41 & 0.11 \\
10 & 60.4 & 12.1 & 30.5 & 0.3 & 33.2 & 0.4 & 4.11 & 0.56 & 7.90 & 2.46 \\
11 & 47.8 & 3.5 & 30.2 & 1.0 & 32.5 & 1.1 & 3.70 & 0.29 & 6.37 & 0.57 \\
12 & 42.4 & 2.8 & 28.8 & 0.5 & 31.9 & 0.7 & 3.23 & 0.41 & 7.59 & 0.53 \\
\hline
\end{tabular}

Cuadro 2. Rendimientos de producción de los tres ciclos cortos (CC) no afectados y los dos ciclos largos (CL) afectados por enfermedades bacterianas en estanques de cultivo de Litopenaeus vannamei (Golfo de Nicoya, Costa Rica)

\begin{tabular}{|c|c|c|c|c|c|c|c|c|c|c|c|c|c|c|}
\hline Ciclos & $\begin{array}{c}\text { Área } \\
\text { (ha) }\end{array}$ & $\begin{array}{c}\text { Total } \\
\text { sembrado } \\
(\mathrm{x} 1000)\end{array}$ & $\begin{array}{c}\text { Dens. } \\
\text { Siembra } \\
\left(\mathrm{m}^{2}\right)\end{array}$ & $\begin{array}{l}\text { Dens. } \\
\text { Final } \\
\left(\mathrm{m}^{2}\right)\end{array}$ & Dias & $\begin{array}{l}\text { Peso } \\
(\mathrm{g})\end{array}$ & $\begin{array}{l}\text { Sobr. } \\
(\%)\end{array}$ & $\begin{array}{l}\text { Crecim } \\
(\mathrm{g} / \mathrm{sem})\end{array}$ & $\begin{array}{c}\text { Biomasa } \\
(\mathrm{kg} / \mathrm{ha})\end{array}$ & $\begin{array}{l}\text { Biomasa } \\
\text { por millar } \\
\text { (total } / \mathrm{kg} \text { ) }\end{array}$ & TOC & $\underset{(\mathrm{kg})}{\text { Alim. }}$ & C.A. & $\begin{array}{c}\text { T.A. } \\
(\mathrm{kg} \\
\left.\mathrm{alim} / \mathrm{ha}{ }^{*} \mathrm{~d}\right)\end{array}$ \\
\hline $\mathrm{CC} \mathrm{I}$ & 22.0 & 2184.0 & $10.1 \pm 0.6$ & $6.7 \pm 1.3$ & $97 \pm 12$ & $13.3 \pm 2.3$ & $66.6 \pm 11.3$ & $0.96 \pm 0.10$ & $898 \pm 251$ & 8.8 & 0.5 & 24263 & $1.27 \pm 0.16$ & $611.70 \pm 2.96$ \\
\hline CC II & 23.2 & 2420.0 & $9.8 \pm 2.6$ & $6.4 \pm 0.6$ & $98 \pm 15$ & $15.7 \pm 1.7$ & $60.6 \pm 6.6$ & $1.14 \pm 0.14$ & $1000 \pm 103$ & 9.9 & 0.6 & 28740 & $1.21 \pm 0.29$ & $12.28 \pm 2.46$ \\
\hline CC III & 28.8 & 2689.6 & $9.2 \pm 1.3$ & $5.7 \pm 0.9$ & $102 \pm 22$ & $216.4 \pm 2.6$ & $62.0 \pm 4.3$ & $1.14 \pm 0.11$ & $926 \pm 120$ & 10.6 & 0.6 & 32647 & $1.17 \pm 0.27$ & $10.61 \pm 1.17$ \\
\hline Totales & & 7293.5 & & & & & & & & & & 85650 & & \\
\hline Promedios & 24.7 & & 9.7 & 6.3 & 99 & 15.2 & 63.1 & 1.08 & 941 & 9.8 & 0.6 & & 1.22 & 11.53 \\
\hline $\mathrm{DE}$ & 3.6 & & 0.5 & 0.5 & 2 & 1.6 & 3.2 & 0.10 & 53 & 0.9 & & & 0.05 & 0.85 \\
\hline Covar $(\%)$ & & & & & & & & & 6 & & & & & \\
\hline CL I & 32.7 & 3439.7 & $10.5 \pm 0.7$ & $3.4 \pm 1.3$ & $108 \pm 21$ & $20.8 \pm 2.0$ & $33.0 \pm 12.1$ & $1.38 \pm 0.21$ & $711 \pm 257$ & 7.1 & 0.4 & 30782 & $1.30 \pm 0.41$ & $8.27 \pm 3.17$ \\
\hline CLII & 32.8 & 3221.0 & $8.9 \pm 2.1$ & $3.7 \pm 0.8$ & $118 \pm 33$ & $19.7 \pm 3.4$ & $37.5 \pm 7.8$ & $1.20 \pm 0.19$ & $722 \pm 198$ & 7.3 & 0.3 & 35820 & $1.57 \pm 0.64$ & $9.32 \pm 2.08$ \\
\hline Totales & & 6660.7 & & & & & & & & & & 66602 & & \\
\hline Promedio & 32.7 & & 9.7 & 3.6 & 113 & 20.3 & 35.3 & 1.29 & 717 & 7.2 & 0.3 & & 1.43 & 8.79 \\
\hline $\mathrm{DE}$ & 0.1 & & 1.1 & 0.2 & 7 & 0.8 & 3.2 & 0.12 & 8 & 0.1 & & & 0.19 & 0.74 \\
\hline Covar $(\%)$ & & & & & & & & & 1 & & & & & \\
\hline
\end{tabular}

sentaron durante las mañanas de abril, julio y diciembre, mientras que en las tardes fueron superiores a $33^{\circ} \mathrm{C}$ en mayo, setiembre y octubre, con la máxima en agosto $\left(>34^{\circ} \mathrm{C}\right)$. El oxígeno disuelto presentó los valores más bajos en las mañanas $(2.69 \pm 0.46 \mathrm{mg} / \mathrm{l}) \mathrm{de}$ mayo y los más altos $(4.97 \pm 2.70 \mathrm{mg} / \mathrm{l})$ en agosto, mientras que fluctuó entre 3.03 y 4.24 $\mathrm{mg} / \mathrm{l}$ el resto del año. Durante las tardes, los valores fluctuaron de $6.28 \mathrm{a} 7.90 \mathrm{mg} / \mathrm{l}$. El agua fue más clara en octubre (turbidez de $60.4 \pm$ $12.1 \mathrm{~cm})$ y más turbia en julio $(39.2 \pm 6.4 \mathrm{~cm})$, sin presentar mayores variaciones, con rangos de 44.6 a $47.8 \mathrm{~cm}$ durante el resto del año. 
Los rendimientos de producción de los tres ciclos sin afectación severa por enfermedades, así como los de dos ciclos con mayor afectación se presentan en el Cuadro 2 . Los rendimientos de producción en las fincas afectadas por enfermedades se redujeron a pesar de los esfuerzos por llevar los camarones a tallas más grandes con el fin de tratar de compensar la biomasa perdida, lo cual se demuestra por medio de la TOC y la biomasa por millar de poslarvas. La caída en la sobrevivencia fue muy drástica y el aumento en peso fue reducido como para lograr esa compensación. Además, al invertir mayor tiempo en tratar de alcanzar tallas más grandes se tuvo que reducir el número de ciclos al año. Los resultados muestran una drástica disminución en la tasa de sobrevivencia de los ciclos más afectados por las enfermedades $(35.3 \pm 3.2 \%)$ con respecto a los menos afectados $(63.1 \pm 3.2 \%)$, determinando una reducción en la densidad de cultivo $(3.6 \pm$ $0.2 / \mathrm{m}^{2}$ ) en los cultivos de dos ciclos, dándose una relación inversa con respecto a la tasa de crecimiento $(1.29 \pm 0.12 \mathrm{~g} / \mathrm{semana})$ en comparación con los cultivos de tres ciclos $\left(6.3 \pm 0.5 / \mathrm{m}^{2}\right.$ y $1.08 \pm 0.10 \mathrm{~g} /$ semana, respectivamente).

Las tasas de crecimiento, en gramos por semana, se presenta en la Figura 3. El peso final fue de $20.3 \pm 0.8 \mathrm{~g}$ para las fincas afectadas por patologías y de $15.2 \pm 1.6 \mathrm{~g}$ en las que no fueron afectadas. Los valores de TEC se exponen en la Figura 4 para ambos ciclos de producción. La relación entre las tasas de crecimiento obtenido en los camarones cultivados y las salinidades en los estanques durante 2015 para los cultivos de dos y tres ciclos se presentan en la Figura 5.

Se intentó ajustar la TA a la reducción en la sobrevivencia y la densidad de cultivo en los cultivos de dos ciclos $(8.79 \pm 0.74 \mathrm{~kg}$ alim/ha*d) en comparación a los de tres ciclos (11.53 $\pm 0.85 \mathrm{~kg}$ alim/ha*d); sin embargo, no se logró disminuir la CA $(1.43: 1.0 \mathrm{y}$ 1.22:1.0, respectivamente). La producción final fue directamente proporcional a la sobrevivencia e independiente del tamaño al- canzado a la cosecha $(941 \pm 53 \mathrm{~kg} / \mathrm{ha}$ con un COVAR de $6 \%$ en los cultivos de tres ciclos y de $717 \pm 8 \mathrm{~kg} /$ ha con un COVAR de $1 \%$ en los de dos ciclos). Asimismo, en los cultivos de dos ciclos se redujo substancialmente la productividad (1434 kg/ha*año) llegando a ser casi la mitad de lo producido en los cultivos de tres ciclos (2823 kg/ha*año). La evaluación del rendimiento de la producción según la TOC y la biomasa por millar de poslarvas generó valores más altos en los cultivos de tres ciclos $(\mathrm{TOC}=0.6$ y $9.8 \pm 0.9 \mathrm{~kg} / 1000)$ que en los de dos ciclos (TOC $=0.3$ y $7.2 \pm$ $0.1 \mathrm{~kg} / 1000$ ).

Las tasas de crecimiento en ambos sistemas de cultivo estuvieron arriba del crecimiento teórico esperado de un gramo por semana. Al crecer más rápido a una menor densidad se alcanzaron mayores pesos a la cosecha $(20.3 \pm 0.8 \mathrm{~g})$ en las fincas afectadas con respecto a las que no fueron afectadas $(15.2 \pm 1.6 \mathrm{~g})$, pero con una mayor duración en los ciclos de cultivo (113 \pm 7 días en vs. $99 \pm 2$ días, respectivamente). A pesar de que en apariencia existió una compensación en la tasa de crecimiento en los cultivos de dos ciclos, la TEC fue similar entre ambos ciclos de producción, mostrando una tendencia a disminuir con el paso de los días de cultivo.

Con respecto a la relación entre la tasa de crecimiento del camarón y grado de salinidad, se observó una reducción paulatina en la salinidad (de 42 a $30 \mathrm{~g} / \mathrm{l}$ ) de marzo a agosto con algunos descensos pronunciados debido a lluvias fuertes, esporádicas y focalizadas en mayo y agosto, seguidas por veranillos al mes siguiente. A partir de septiembre bajó rápidamente de los $30 \mathrm{~g} / 1$ hasta llegar al mínimo de $17 \mathrm{~g} / 1$ en noviembre debido a lluvias fuertes y constantes. En diciembre disminuyeron las lluvias y aumentó la salinidad hasta $20 \mathrm{~g} / 1$. Después de cada descenso en la salinidad hubo un efecto positivo en la tasa de crecimiento del camarón en los dos sistemas de cultivo. El incremento en peso fue más pronunciado cuando la salinidad bajó de 30 a $17 \mathrm{~g} / 1$ con un promedio de $23.5 \mathrm{~g} / \mathrm{l}$ en 


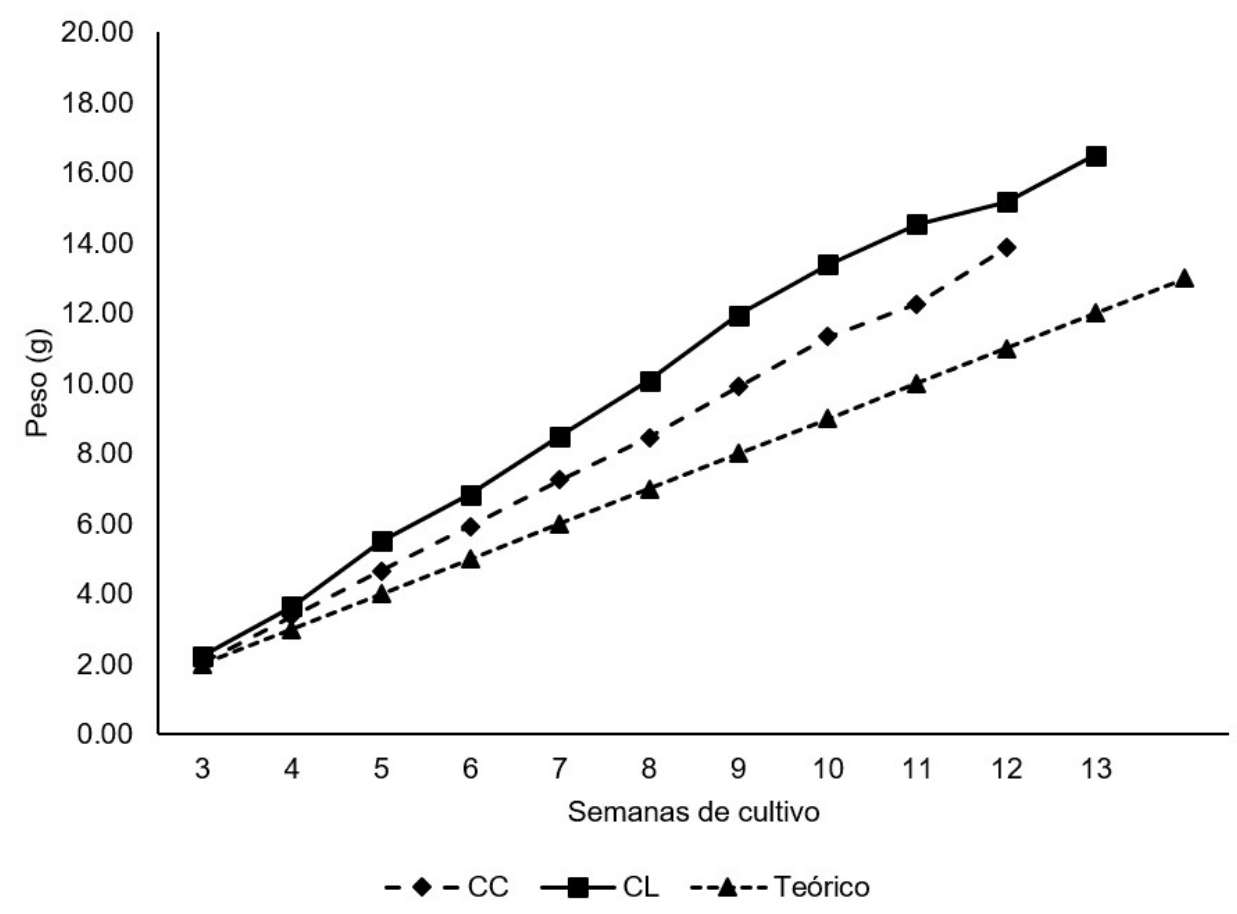

Figura 3. Incremento de peso de Litopenaeus vannamei en cultivos en tres ciclos (sin patologías severas) (CC) y en el de dos ciclos (con enfermedades severas) (CL) en fincas camaroneras del Golfo de Nicoya, Costa Rica (2015)

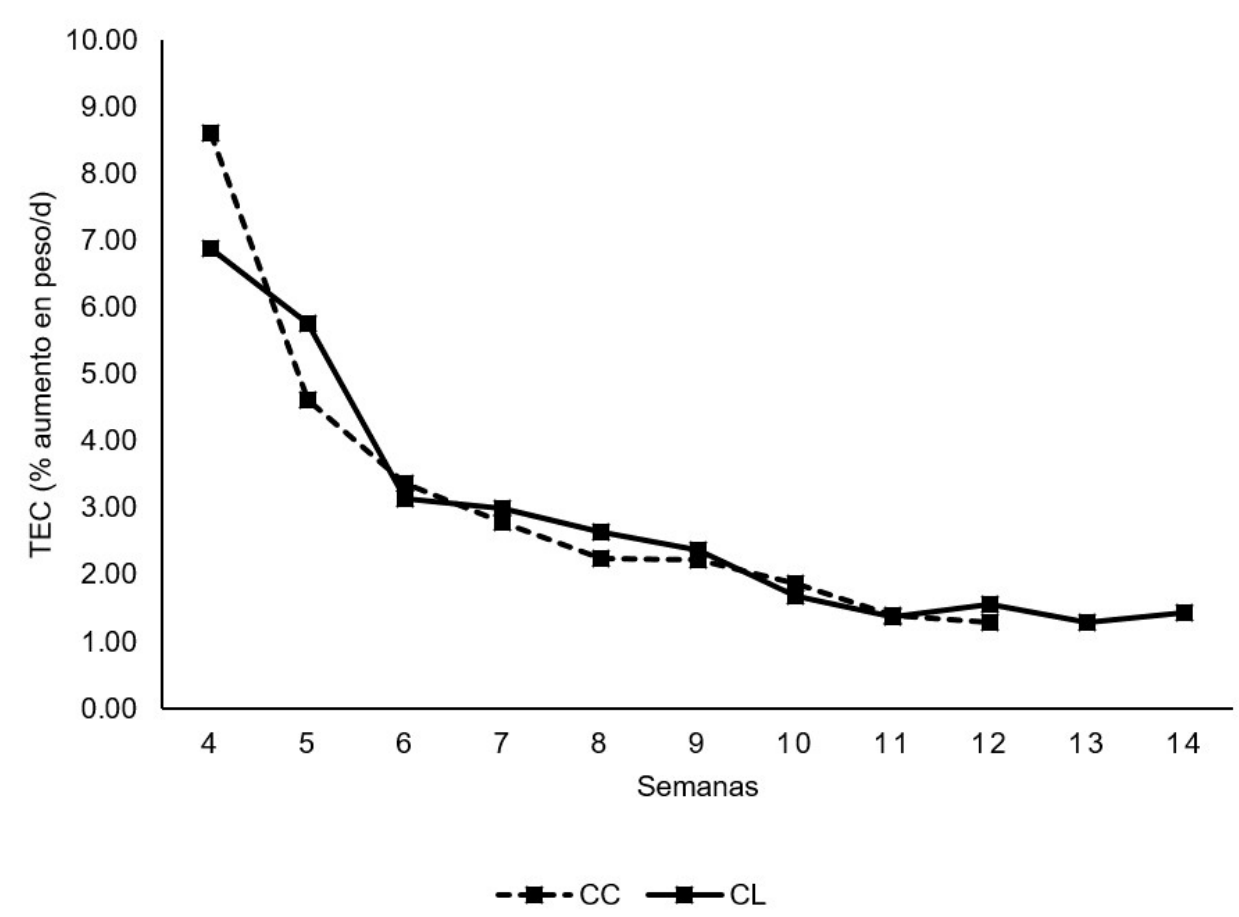

Figura 4. Tasa especítica de crecimiento (\% aumento en peso/día) de Litopenaeus vannamei en el cultivo de tres ciclos (sin patologías severas) (CC) y en el de dos ciclos (con enfermedades severas) (CL) en fincas camaroneras del Golfo de Nicoya, Costa Rica (2015) 
ambos ciclos durante los últimos tres meses de cultivo.

Fue común encontrar gran disparidad de tallas entre los individuos. En la cosecha de emergencia en las fincas más afectadas se encontraban camarones pequeños de $6 \mathrm{a} 9 \mathrm{~g}$, moribundos y severamente afectados, que representaban el $30-40 \%$ de la población muestreada. Estos camarones se mantienen en las orillas mostrando una condición débil con características sugerentes de desnutrición (animales vacíos, flacos, pálidos, con caparazón flojo y quebradizo) y enfermos (branquias sucias, colas verdes, pleópodos rojos u oscuros, hepatopáncreas pálido y de reducido tamaño y nado errático en la superficie). El canibalismo sobre estos camarones moribundos fue considerable y se evidenció por el crecimiento desproporcionado, de hasta 3 a 4 g por semana, que tuvieron los camarones sobrevivientes a la semana siguiente del evento de mortalidad.

Las principales infecciones y síndromes detectados en tejidos y órganos durante 2015 se presentan en el Cuadro 3. En el diagnóstico en fresco se observó presencia leve a severa de gregarinas, epibiontes y bacterias filamentosas sin lesiones asociadas. Algunas de las gregarinas encontradas en el intestino se presentan en la Figura 6A, cuya morfología es compatible con la reportada para la especie Nematopsis sp (Lightner, 1996; Morales-Covarrubias, 2010), En algunos camarones se observaron urópodos ligeramente enrojecidos, con bordes verdes, así como presencia leve de ectoparásitos en apéndices (principalmente protozoarios), sin lesiones asociadas (G2) (Figura 6B). En camarones muy afectados, el hepatopáncreas presentaba encapsulaciones hemocíticas multifocales, fuertemente melanizadas involucrando múltiples túbulos, regiones necróticas, atrofia general y pérdida de pigmentación en la cápsula (Figura 6C), los cuales fueron clasificados en grados G3 a G4.
Los resultados de análisis en fresco según la cantidad y el porcentaje de prevalencia aparente, así como el grado de severidad de la infección en el hepatopáncreas se presentan en el Cuadro 4. Camarones normales sin signos clínico-patológicos, excepto por alguna palidez en el hepatopáncreas, presentaron una disminución en reservas lipídicas, escasa infiltración hemocítica, leves estrangulaciones tubulares apicales, atrofia moderada del hepatopáncreas y, en algunos casos, pérdida de pigmentación en la cápsula. Las lesiones fueron clasificadas en grados G0 a G2 con una prevalencia aparente del 10 al $20 \%$ de las muestras. Paralelamente, se detectaron algunos casos sugerentes de NHP.

Hepatopáncreas con daños y pérdida de las reservas lipídicas, unido a la presencia de escasas bacterias extracelulares y mótiles, sugiere que fueron afectados por H. penaei; principalmente debido a la presencia endémica del patógeno en la región y a la integración de las observaciones clínico-patológicas. En algunas muestras se realizó confirmación del NHP mediante histopatología (datos no mostrados). Se clasificaron en grado de G2 a G4 con una prevalencia aparente de 10 a $30 \%$. En estos camarones bajo condiciones de estrés, fue posible detectar mediante análisis bacteriológico, niveles altos, pero dentro de rangos normales de colonias sacarolíticas (amarillas), no bioluminiscentes, con colonias de diferentes formas y tamaños.

Casos más severos con picos de alta mortalidad ocurrieron principalmente durante los periodos de muda, cuando se observaba la presencia de aves cazando camarones moribundos y muertos. En estos casos, el hepatopáncreas presentaba lo daños descritos en la Figura 6C. Algunos casos presentaron edema. Estas lesiones fueron clasificadas en grados $\mathrm{G} 2$ a G4, con una prevalencia aparente de 20 a $90 \%$.

Algunos resultados de conteos bacteriológicos del hepatopáncreas durante eventos de alta mortalidad se presentan en el 

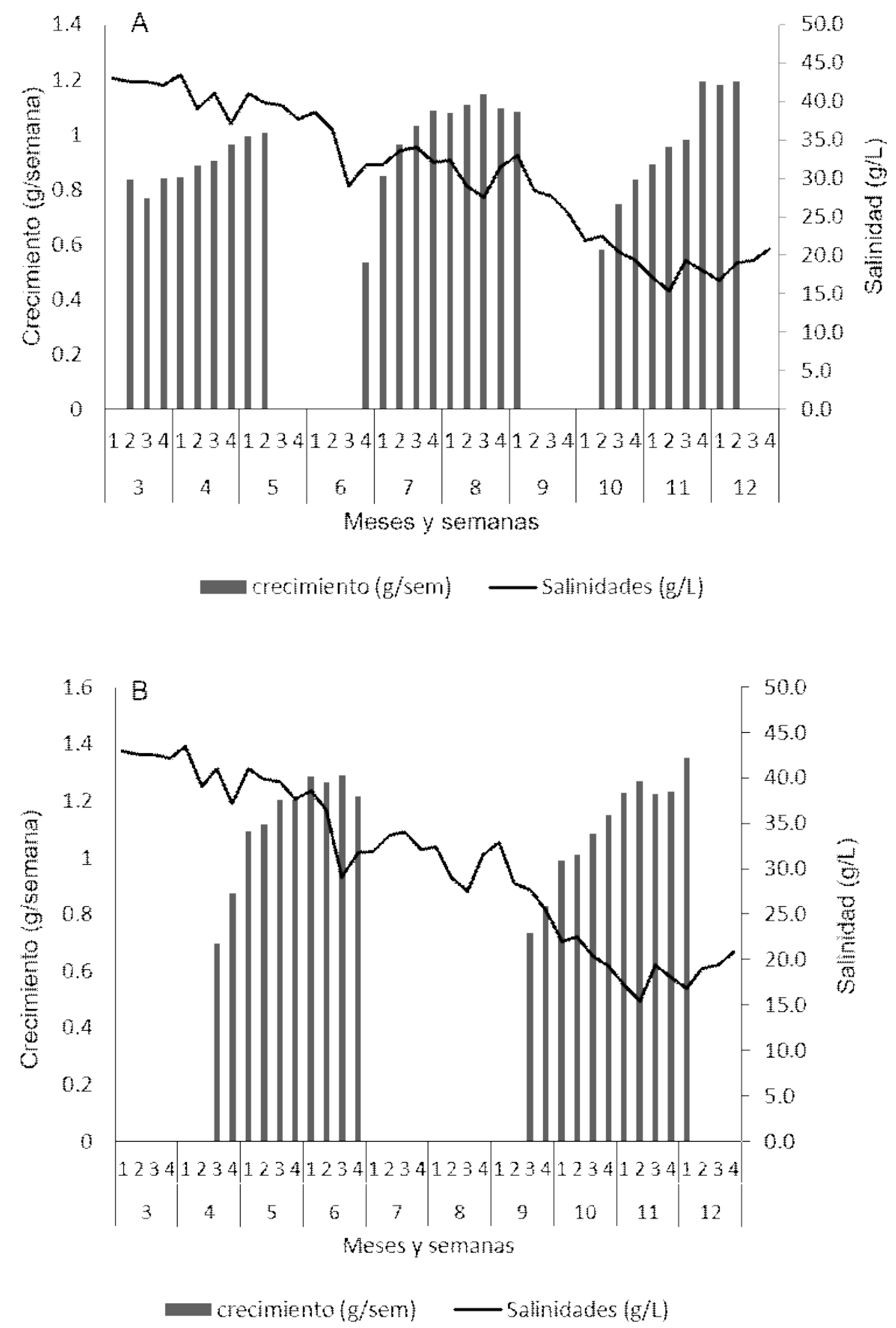

Figura 5. Relación entre la salinidad (g/l) y el crecimiento de Litopenaeus vannamei (g/semana) medidos semanalmente en (A) el cultivo de tres ciclos (sin patologías severas) y en (B) el de dos ciclos (con enfermedades severas) en fincas camaroneras del Golfo de Nicoya, Costa Rica (2015) 
Cuadro 3. Grado de severidad de las principales infecciones, infestaciones y síndromes encontrados en Litopenaeus vannamei en fincas camaroneras del Golfo de Nicoya, Costa Rica (2015)

\begin{tabular}{|c|c|c|}
\hline Tejido / órgano & Observaciones & Grado \\
\hline Hepatopáncreas & $\begin{array}{l}\text { Cuatro individuos presentan desprendimientos celulares } \\
\text { moderados y disminución de reservas lipídicas. } \\
\text { Pérdida de pigmentos de la cápsula hepatopancreática. } \\
\text { Uno de los individuos presenta atrofia tubular severa, } \\
\text { infiltración hemocítica inicial sin procesos melaníticos } \\
\text { detectables y leve respuesta inflamatoria. }\end{array}$ & G0-4 \\
\hline Intestino & $\begin{array}{l}\text { Presencia leve de gregarinas de dos o tres células, no se } \\
\text { observan lesiones asociadas. Presencia leve de gametocitos en } \\
\text { intestino posterior. }\end{array}$ & G2 \\
\hline Branquias & $\begin{array}{l}\text { Presencia muy leve de protozoos y bacterias filamentosas Sin } \\
\text { lesiones asociadas. Acumulación leve de detritus en dendo- } \\
\text { branquias. }\end{array}$ & G1 \\
\hline Apéndices & $\begin{array}{l}\text { Urópodos ligeramente enrojecidos, presencia leve de } \\
\text { ectoparásitos en apéndices. Principalmente protozoos, sin } \\
\text { lesiones asociadas. Urópodos con bordes verdes. }\end{array}$ & G2 \\
\hline Cutícula/músculo & No se detectan lesiones, parásitos o patógenos. & G0 \\
\hline $\begin{array}{l}\text { Bacteriología en } \\
\text { hepatopáncreas }\end{array}$ & $\begin{array}{l}\text { 4.6-5.1 x } 10^{3} \mathrm{UFC} / \mathrm{g} \text {, sacarolíticas, no bioluminiscentes. } \\
\text { Convexas, circulares, medianas y pequeñas, regulares. }\end{array}$ & Normal \\
\hline
\end{tabular}

Cuadro 4. Prevalencia y grado de severidad de infecciones en el hepatopáncreas de Litopenaeus vannamei en fincas camaroneras del Golfo de Nicoya, Costa Rica (2015)

\begin{tabular}{cccc}
\hline \multirow{2}{*}{ Estanque } & \multicolumn{2}{c}{$\begin{array}{c}\text { Prevalencia } \\
\text { aparente }\end{array}$} & $\begin{array}{c}\text { Severidad } \\
\text { (grados) }\end{array}$ \\
\cline { 2 - 3 } & (n) & $(\%)$ & \\
\hline 1 & 2 & 20 & G0-G2 \\
2 & 1 & 10 & G0-G2 \\
3 & 1 & 10 & G0-G2 \\
4 & 3 & 30 & G2-G4 \\
5 & 6 & 60 & G3-G4 \\
6 & 1 & 10 & G0-G2 \\
7 & 1 & 10 & G2 \\
8 & 2 & 20 & G3-G4 \\
9 & 2 & 20 & G3-G4 \\
10 & 9 & 90 & G3-G4 \\
11 & 2 & 20 & G0-G2 \\
12 & 1 & 10 & G0-G4 \\
\hline
\end{tabular}

Cuadro 5. Todos los conteos fueron superiores a $100000 \mathrm{UFC/g}$ de hepatopáncreas. Por último, no se observaron casos con signos clínico-patológicos o mortalidades que hicieran sospechar de incidencias por infecciones virales como la mancha blanca.

\section{Discusión}

La intensidad y duración del periodo cálido fue similar al episodio más fuerte registrado durante el fenómeno de El Niño en 1997 (Solano, 2015); asimismo, los ciclos de cultivo en 2015 también iniciaron con una salinidad $8 \mathrm{~g} / \mathrm{l}$ más alta que en los dos años previos, manteniéndose en ese rango de superioridad hasta octubre cuando empezaron las lluvias. Setiembre y octubre fueron los meses que manifestaron el mayor impacto del efecto de El Niño en 2015, ya que son los 
Cuadro 5. Litopenaeus vannamei en fincas camaroneras del Golfo de Nicoya, Costa Rica: resultados bacteriológicos de macerados de hepatopáncreas (UFC/g, en miles) suspendidos en soluciones isotónicas estériles (2015)

\begin{tabular}{cccc}
\hline Estanque & UFC total & Sacarolíticas & No sacarolíticas \\
\hline 1 & 160 & 40 & 120 \\
2 & 384 & 24 & 360 \\
3 & 460 & 460 & $<1$ \\
4 & 300 & 300 & $<1$ \\
5 & 216 & 216 & $<1$ \\
6 & 160 & 150 & 10 \\
7 & 231 & 230 & 1 \\
8 & 211 & 211 & $<1$ \\
9 & 194 & 194 & $<1$ \\
\hline
\end{tabular}

meses que normalmente aportan la mayor cantidad de lluvias al año en esta región del país (Alvarado et al., 2012). Altas temperaturas $\left(>31{ }^{\circ} \mathrm{C}\right)$ y salinidades $(>30 \mathrm{~g} / 1)$ durante periodos prolongados de tiempo $(>45-60$ días de cultivo) son los factores más importantes que predisponen el desarrollo de enfermedades bacterianas (Saborio y Rojas, 2002; Morales-Covarrubias, 2010; Varela y Peña, 2015a).

La temperatura matinal del agua durante 2015 estuvo dentro del rango considerado normal para el cultivo de camarones marinos $\left(28-30^{\circ} \mathrm{C}\right)$, según varios autores (Boyd, 1989; Scura, 1995; van Wyk y Scarpa, 1999; Ferreira et al., 2011); sin embargo, los valores de las tardes sobrepasaron el rango normal en $2-4{ }^{\circ} \mathrm{C}$. Temperaturas superiores a $4{ }^{\circ} \mathrm{C}$ de lo esperado son suficientes para provocar condiciones de estrés en los camarones que pueden incidir sobre la aparición de enfermedades bacterianas (MoralesCovarrubias, 2010; Olivas et al., 2010; Varela y Peña, 2015a). El estrés aumenta la susceptibilidad del camarón ante los patógenos; siendo las bacterias las causantes de los mayores estragos en los rendimientos de producción (Lightner, 1996; Saborio y Rojas, 2002;
Tran et al., 2013; Peña y Varela, 2016). Es así que se presentaron reducciones importantes en los rendimientos y en las ganancias de producción, dependiendo de la densidad de siembra, en concordancia con lo reportado por Villanueva et al. (2013).

Los niveles de oxígeno disuelto permanecieron dentro de los rangos considerados como normales (Boyd, 1989); es así que los valores oscilaron entre 3 y $5 \mathrm{mg} / 1$, sobrepasando niveles que podrían ser causantes de estrés $(2.0 \mathrm{mg} / \mathrm{l})($ Kramer, 1975) o mortalidad (1.0 mg/l) (Martínez et al. 1998). El nivel de oxígeno disuelto en las tardes se mantuvo relativamente constante a lo largo del año revelando un buen manejo de la productividad natural generada por la densidad del fitoplancton. Esto permitió que las lecturas del disco Sechii estuvieran dentro de un rango considerado aceptable (40-50 cm de visibilidad).

No se logró alcanzar el crecimiento compensatorio esperado. Este crecimiento fue solamente observado de manera parcial entre las fases de maternidad y engorde, en las cuales se generó un cambio drástico en la densidad de siembra de 80 a 9 camarones $/ \mathrm{m}^{2}$ 


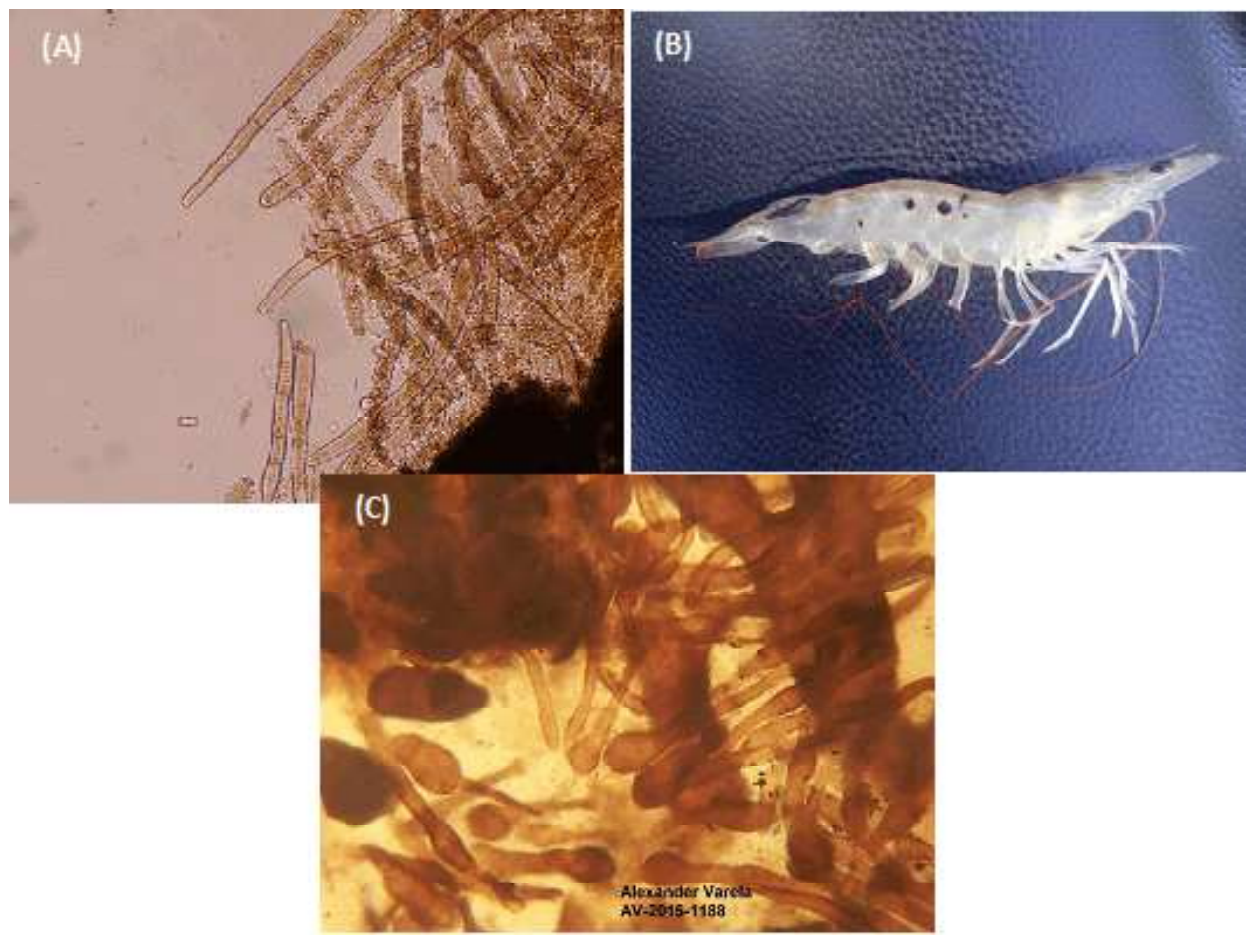

Figura 6. Lesiones en Litopenaeus vannamei en fincas camaroneras del Golfo de Nicoya, Costa Rica (2015). (A) Presencia de gregarinas en el contenido intestinal: abundancia de parásitos en estadios de sicigias de 2 a 4 divisiones. G4. Sin tinción, 400X. (B) Camarones aparentemente estresados o enfermos: es común la aparición de oscurecimientos en la cutícula causados por la acumulación de melanina; además, se puede producir coloraciones rojizas en los bordes de los pleópodos y antenas, así como cambios de color en branquias. (C) Hepatopáncreas severamente dañado por bacterias: se observan túbulos melanizados, así como áreas de encapsulación hemocítica, lo que limita la capacidad del órgano en sus funciones digestivas, que llega a producir alta mortalidad. Sin tinción, 400X

(Valverde-Moya y Alfaro-Montoya, 2015). La tasa específica de crecimiento (TEC) demuestra la nula compensación del crecimiento al ser muy similar entre las fincas afectadas y no afectadas, teniendo una tendencia a ir disminuyendo conforme transcurren los ciclos de cultivo. La tasa de crecimiento mejoró en todas las fincas cuando la salinidad bajó de 30 a $17 \mathrm{~g} / 1$ con un promedio de $23.5 \mathrm{~g} / 1$ producto de las lluvias. Resultados similares se han reportado en salinidades de $25 \mathrm{~g} / 1$, mientras que la sobrevivencia no se afectó en salinidades de 10 a 35 g/l (Ye et al., 2009).
La leve presencia de parásitos intestinales y externos, así como de bacterias filamentosas en branquias y apéndices afectaron muy poco los cultivos. La baja infestación de parásitos pudo estar relacionada a la sequía existente, así como al escaso incremento de la biomasa en las fincas afectadas por enfermedades bacterianas y la reducción en la tasa de alimentación. Diversos estudios señalan que la presencia de epibiontes, asociada a necrosis y melanosis, es una condición de camarones cultivados en estanques con exceso de materia orgánica, debido prin- 
cipalmente a las altas densidades de cultivo y elevados niveles de alimentación utilizados (Olivas et al., 2010; Varela y Peña, 2012).

Los resultados de bacteriología son consistentes con infecciones bacterianas por Vibrio sp. La clínica y el análisis en fresco sugieren, además, una posible infección crónica por Hepatobacter penaei (NHP). La mortalidad observada en todos los estanques con conteos de colonias no sacarolíticas bioluminiscentes superiores a $1000 \mathrm{UFC} / \mathrm{g}$ está, en muchos casos, ligada a la presencia de $V$. harveyi (Mugnier et al., 2013), especie considerada potencialmente patógena para los camarones (Olivas et al., 2010). Se presentó irregularidad y variabilidad entre las microbiotas de los camarones, basados en la morfología, tamaño y color de las colonias recuperadas en el agar, entre convexas, circulares, regulares y pequeñas.

Los eventos de mortalidad se dieron mayormente después de periodos de mudas fuertes con presencia de gaviotas cazando de manera intermitente en los estanques afectados. Los camarones presentaban intestino con contenido variable y hepatopáncreas con palidez. Durante las mudas, el camarón se entierra en el fondo y está energéticamente debilitado, haciéndose más susceptible a enfermedades. Los estadios de pre-muda tardía y pos-muda temprana parecen ser los más susceptibles (Mugnier et al., 2013).

Los camarones medianos, con tallas entre 9 y $12 \mathrm{~g}$, y los camarones grandes, con tallas entre 12 y $15 \mathrm{~g}$, se presentaron como normales sin signos de enfermedad. Estos fueron considerados como camarones sanos y bien nutridos que lograron superar la enfermedad (medianos) o no llegaron a enfermarse (grandes). Ávila-Villa et al. (2012) indican que el camarón es capaz de mantener un estado de homeostasis conocido como el síndrome de la adaptación general, donde puede hacerle frente a la enfermedad durante las primeras fases de desarrollo; es por ello, que las mortalidades no son tan altas durante las primeras fases de desarrollo de la enfer- medad para los camarones mejor preparados fisiológicamente (Alpuche et al., 2005).

Las infecciones por Vibrio sp y de Hepatobacter penaei son las más comunes en Latinoamérica (Saborio y Rojas, 2002; Olivas et al., 2010; Peña y Varela, 2016) causando grandes estragos económicos. Ambos tipos de bacterias se consideran patógenos de camarones con el sistema inmune deprimido debido a condiciones ambientales desfavorables (Ballamoole et al., 2014). Las características y modos de acción de estas enfermedades bacterianas han sido ampliamente estudiadas (Prieto y Rodríguez, 1993; Lightner, 1996; Morales y Cuellar-Anjel, 2008; Morales-Covarrubias, 2010; Varela y Peña, 2015b).

Paradójicamente, las elevadas temperaturas del agua de cultivo durante 2015 actuaron como factor de protección ante el virus de la mancha blanca, no habiéndose encontrado casos positivos. Esta virosis fue común en años anteriores por las bajas temperaturas $\left(<27^{\circ} \mathrm{C}\right)$ en las noches y las variaciones bruscas con respecto al día por la entrada de los vientos alisios fuertes del Norte (Valverde-Moya y Alfaro-Montoya, 2013; Varela y Peña, 2014). Múltiples estudios han demostrado que elevadas temperaturas en el agua tienen un efecto negativo en la replicación del virus de la mancha blanca (Rahman et al., 2007; Varela y Peña, 2010; Gao et al., 2011; Moser et al., 2012).

\section{Conclusiones}

- Las condiciones propias del fenómeno de El Niño en 2015 trajeron como consecuencias elevadas temperaturas y salinidades en el agua de los estanques con cultivo de camarones en el Golfo de Nicoya, Costa Rica.

- Las condiciones ambientales extremas generaron infecciones y mortalidades, en muchos casos severas, con participación de especies de bacterias del género 
Vibrio, así como de la bacteria intracelular Hepatobacter penaei (NHP).

- No se presentaron casos positivos relacionados al virus de la mancha blanca.

- Los impactos económicos de estos eventos estuvieron directamente relacionados a la estrategia de producción de cosechar de emergencia el camarón relativamente pequeño o continuar el cultivo con los animales sobrevivientes. No se encontró un beneficio económico en continuar los cultivos hasta tallas más grandes luego de eventos de mortalidades severas.

\section{Literatura Citada}

1. Alpuche J, Pereyra A, Agundis C. 2005. Respuestas bioquímicas de camarones marinos a factores ambientales. REDVET 6(5). [Internet]. Disponible en: http://www.veterinaria.org/revistas/ redvet/n050505/050508.pdf

2. Alvarado L, Contreras W, Alfaro M, Jiménez E. 2012. Escenarios de cambio climático regionalizados para Costa Rica. Departamento de Climatología e Investigaciones Aplicadas del IMN, MINAET. $52 \mathrm{p}$.

3. Alvarado L. 2015. Estado actual y pronóstico del fenómeno ENOS. Departamento de Climatología e Investigaciones Aplicadas del IMN, Costa Rica.

4. Ávila-Villa L, Fimbres-Olivarria D, García-Sánchez G, Gollas-Galván T, Hernández-López J, MartínezPorchas M. 2012. Physiological and immune responses of white shrimp (Litopenaeus vannamei) infected with necrotizing hepatopancreatitis bacterium. Aquaculture 324-325: 14-19. doi: 10.1016/j.aquaculture.2011.09.010

5. Ballamoole $K$, Vijaya $K$, Juliet $R$, Mohan R, Praveen $R$, Balligavi $M$, Iddya K, Indrani K. 2014. Diversity of Vibrio parahaemolyticus associated with disease outbreak among cultured
Litopenaeus vannamei (Pacific white shrimp) in India. Aquaculture 433: 247251. doi: $10.1016 /$ j.aquaculture.2014.06.016

6. Boyd C. 1989. Water quality management and aeration in shrimp farming. Alabama, USA: Auburn University. 84 p.

7. Cuéllar-Anjel, J. 2008. Métodos de diagnóstico de enfermedades en camarones. En: Morales V, Cuéllar-Anjel J (eds). Guía técnica - Patología e inmunología de camarones penaeidos. Panamá: Programa CYTED Red II-D Vannamei. p 1-52.

8. Ferreira N, Boneti C, Seiffert W. 2011. Hydrological and water quality indices as management tools in marine shrimp culture. Aquaculture 318: 425-433. doi: 10.1016/j.aquaculture.2011.05.045

9. Gao H, Kong J, Li Z, Xiao G, Meng $X .2011$. Quantitative analysis of temperature, salinity and $\mathrm{pH}$ on WSSV proliferation in Chinese shrimp Fenneropenaeus chinensis by real-time PCR. Aquaculture 32: 26-31. doi: 10.1016/j.aquaculture.2010.12.022

10. García C, Perlado R. 2014. Impactos del cambio climático sobre la acuicultura en España. Madrid, España: Ministerio de Agricultura, Alimentación y Medio Ambiente. $38 \mathrm{p}$.

11. Kramer GL. 1975. Studies on the lethal dissolved oxygen levels for young brown shrimp, Penaeus aztecus Ives. World Aquaculture Soc 6: 157-167. doi: 10.1111/ j.1749-7345.1975.tb00014.x

12. Lightner DV. 1996. A handbook of shrimp pathology and diagnostic procedures for diseases of cultured penaeid shrimp. Louisiana, USA: World Aquaculture Society. 304 p.

13. Martínez E, Aguilar M, Trejo L, Hernández I, Díaz-Iglesia E, Soto LA, Sánchez A, Rosas C. 1998. Lethal low dissolved oxygen concentrations for postlarvae and early juvenile Penaeus setiferus at different salinities and $\mathrm{pH}$. World Aquaculture Soc 29: 221-229. doi: 10.1111/j.1749-7345.1998.tb00980.x 
14. Morales V, Cuéllar-Anjel J. 2008. Guía técnica - Patología e inmunología de camarones penaeidos. Panamá: Programa CYTED Red II-D Vannamei. $270 \mathrm{p}$.

15. Morales V, Cuellar-Anjel J. 2014. Guía técnica. Patología e inmunología de camarones penaeidos. Panamá: OIRSA. $382 \mathrm{p}$.

16. Morales-Covarrubias M. 2008. Enfermedades bacterianas. En: Morales V, Cuéllar-Anjel J (eds). 2008. Guía técnica - Patología e inmunología de camarones penaeidos. Panamá: Programa CYTED Red II-D Vannamei. p 117-134.

17. Morales-Covarrubias MS. 2013. $\mathrm{Ca}-$ marón. Análisis en fresco herramienta de diagnóstico. México: CIAD-OIRSA. $86 \mathrm{p}$.

18. Morales-Covarrubias, M. 2010. Enfermedades del camarón: detección mediante análisis en fresco e histopatología. México: Ed. Trillas. $122 \mathrm{p}$.

19. Moser J, Galván D, Mendoza F, Encinas T, Coronado D, Portillo G, Risoleta M, Magallón F, Hernández J. 2012. Water temperature influences viral load and detection of White Spot Syndrome Virus (WSSV) in Litopenaeus vannamei and wild crustaceans. Aquaculture 326-329: 9-14. doi: 10.1016/ j.aquaculture.2011.10.033

20. Mugnier C, Justou C, Lemonnier H, Patrois J, Ansquer D, Goarant C, Lecoz JR. 2013. Biological, physiological, immunological and nutritional assessment of farm-reared Litopenaeus stylirostris shrimp affected or unaffected by vibriosis. Aquaculture 388-391: 105-114. doi: 10.1016/ j.aquaculture.2013.01.010

21. Olivas J, Cáceres J, Vásquez R. 2010. Patógenos que afectan el cultivo de Litopenaeus vannamei en ambiente marino y dulceacuícola en el estado de Baja California, México. REDVET 11(3). [Internet]. Disponible en: http:// www.veterinaria.org/revistas/redvet/ n030310/031020.pdf
22. Peña N, Varela A. 2016. Prevalencia de las principales enfermedades infecciosas en el camarón blanco Penaeus vannamei cultivado en el Golfo de Nicoya, Costa Rica. Rev Biol Marina Oceanografía 51: 553-564. doi: 10.4067/ S0718-19572016000300007

23. Prieto A, Rodríguez MC. 1993. Diagnóstico y control de enfermedades bacterianas en camarón de cultivo. México: FAO. 66 p.

24. Rahman M, Corteel M, Wille M, Alday-Sanz V, Pensaert M, Sorgeloos P, Nauwynck H. 2007. The effect of raising water temperature to $33{ }^{\circ} \mathrm{C}$ in Penaeus vannamei juveniles at different stages of infection with white spot syndrome virus (WSSV). Aquaculture 272: 240-245. doi: 10.1016/j.aquaculture.2007.07.228

25. Saborio A, Rojas A. 2002. Manual sobre enfermedades de camarón de cultivo. Universidad Centroamericana, Nicaragua. $71 \mathrm{p}$.

26. Scura E. 1995. Dry season production problems on shrimp farms in Central America and the Caribean basin. In: Browdy C, Hopkins J (eds). Swimming through troubled waters. Luisiana, USA: World Aquaculture Society. p 200-213.

27. Solano E. 2015. Resumen meteorológico octubre del 2015. Costa Rica: Departamento de Meteorología Sinóptica y Aeronáutica (DMSA) del IMN.

28. Tran L, Nunan L, Redman R, Mohney L, Pantoja C, Fitzsimmons K, Lightner DV. 2013. Determination of the infectious nature of the agent of acute hepatopancreatic necrosis syndrome affecting penaeid shrimp. Dis Aquat Organ 105: 45-55. doi: 10.3354/dao02621

29. Valverde-Moya J, Alfaro-Montoya J. 2013. La experiencia del cultivo comercial de camarones marinos en estanques de producción en Costa Rica. Rev Mar Cost 5: 87-105.

30. Valverde-Moya J, Alfaro-Montoya $J$. 2015. Crecimiento compensatorio y producción en las fases de pre cría, pre engorde y engorde comercial del camarón 
blanco, Litopenaeus vannamei, en Costa Rica. Rev Mar Cost 7: 99-115. doi: 10.15359/revmar.7.7

31. Valverde-Moya J; Alfaro-Montoya, J. 2014. Productividad y rentabilidad del cultivo de camarones marinos en el Golfo de Nicoya, Costa Rica. Rev Mar Cost 6: 37-53. doi: 10.15359/revmar.6.3

32. Van Wyk P, Scarpa J. 1999. Water quality requirements and management. In: Van Wyk P, Davis-Hodgkins M, Laramore R, et al. (eds). Farming marine shrimp in recirculating freshwater systems. Tallahassee, FL, USA: Florida Department of Agriculture and Consumer Services. p 128-138.

33. Varela A, Peña N. 2010. El Virus del Síndrome de las Manchas Blancas (WSSV): una revisión y su impacto en la camaronicultura costarricense. Rev Cienc Vet 28(2): 51-69.

34. Varela A, Peña N. 2012. Efecto de los epibiontes en los sistemas productivos de camarón en Costa Rica. Rev Univ Téc Nac 62: 70-73.

35. Varela A, Peña N. 2014. Fluctuaciones térmicas y su relación con el Virus del Síndrome de las Manchas en Litopenaeus vannamei cultivado en el Golfo de Nicoya. Rev Univ Téc Nac 68: 80-83.
36. Varela A, Peña N. 2015a. Hepatopancreatitis necrotizante asociada al fenómeno del Niño, en cultivos de camarones del Golfo de Nicoya. Repertorio Científico 18(1): 29-34.

37. Varela A, Peña N. 2015b. Histopatología diferencial de tres enfermedades bacterianas que afectan el hepatopáncreas de camarones peneidos. Agron Mesoam 27(1):73-80. doi: 10.15517/ am.v27i1.21887

38. Varela A. 2007. Manual de interpretación de resultados de laboratorio. Perú: Alicorp, Nicovita, Publicis-Asociados.

39. Villanueva $R$, Araneda M, Vela M, Seijo J. 2013. Selecting stocking density in different climatic seasons: a decision theory approach to intensive aquaculture. Aquaculture 384-387: 25-34.

40. Vincent A, Lotz J. 2007. Effect of salinity on transmission of necrotizing hepatopancreatitis bacterium (NHPB) to Kona stock Litopenaeus vannamei. Dis Aquat Org 75: 265-268. doi: 10.3354/ dao075265

41. Ye L, Jiang S, Zhu X, Yang $Q$, Wen $\boldsymbol{W}, \boldsymbol{W u} K$. 2009. Effects of salinity on growth and energy budget of juvenile Penaeus monodon. Aquaculture 290: 140-144. doi: 10.1016/j.aquaculture.2009.01.028 